\title{
The collagen receptor uPARAP/Endo180 in tissue degradation and cancer (Review)
}

\author{
MARIA C. MELANDER ${ }^{1}$, HENRIK J. JÜRGENSEN ${ }^{2}$, DANIEL H. MADSEN ${ }^{2}$, \\ LARS H. ENGELHOLM ${ }^{1}$ and NIELS BEHRENDT ${ }^{1}$ \\ ${ }^{1}$ The Finsen Laboratory, Rigshospitalet/BRIC, The University of Copenhagen, \\ DK-2200 Copenhagen N, Denmark; ${ }^{2}$ Proteases and Tissue Remodeling Section, Oral and \\ Pharyngeal Cancer Branch, NIDCR, National Institutes of Health, Bethesda, MD, USA
}

Received June 8, 2015; Accepted July 20, 2015

DOI: $10.3892 /$ ijo.2015.3120

\begin{abstract}
The collagen receptor uPARAP/Endo180, the product of the MRC2 gene, is a central component in the collagen turnover process governed by various mesenchymal cells. Through the endocytosis of collagen or large collagen fragments, this recycling receptor serves to direct basement membrane collagen as well as interstitial collagen to lysosomal degradation. This capacity, shared only with the mannose receptor from the same protein family, endows uPARAP/ Endo180 with a critical role in development and homeostasis, as well as in pathological disruptions of the extracellular matrix structure. Important pathological functions of uPARAP/ Endo180 have been identified in various cancers and in several fibrotic conditions. With a particular focus on matrix turnover in cancer, this review presents the necessary background for understanding the function of uPARAP/Endo180 at the molecular and cellular level, followed by an in-depth survey of the available knowledge of the expression and role of this receptor in various types of cancer and other degenerative diseases.
\end{abstract}

Correspondence to: Dr Niels Behrendt, The Finsen Laboratory, Rigshospitalet/BRIC, The University of Copenhagen, Ole Maaløes Vej 5, DK-2200 Copenhagen N, Denmark

E-mail: niels.behrendt@finsenlab.dk

Abbreviations: MMP, matrix metalloprotease; uPARAP, urokinase plasminogen activator receptor associated protein; MR, mannose receptor; PLA2R, M-type phospholipase A2 receptor; Fn-II, fibronectin type-II; CTLD, C-type lectin-like domain; CTS, crooked tail syndrome; EMT, epithelial mesenchymal transition; TGF- $\beta$, transforming growth factor- $\beta$; GBM, glioblastoma multiforme; RANKL, receptor activator of nuclear factor- $\mathrm{kB}$ ligand; $\mathrm{CKD}$, chronic kidney disease; ATRA, all trans retinoic acid

Key words: cancer invasion, collagen, extracellular matrix, matrix degradation, CD280, MRC2

\section{Contents}

1. Introduction to collagen remodeling in health and disease 2. uPARAP/Endo180: an endocytic receptor for collagen

3. Functional properties of uPARAP/Endo180 and related receptors

4. Role of uPARAP/Endo180 in the healthy organism

5. Tissue expression and regulation

6. uPARAP/Endo180 in breast and prostate cancer

7. uPARAP/Endo180 in glioma

8. uPARAP/Endol 80 in bone cancer

9. uPARAP/Endo180 in other cancers

10. Expression and role of uPARAP/Endo180 in other pathological conditions

11. Conclusions and perspectives

\section{Introduction to collagen remodeling in health and disease}

One of the hallmarks of cancer is tumor invasion and metastasis. A central process in these events is the degradation of the tumor-surrounding extracellular matrix which is not only a crucial rate-limiting step for tumors to invade adjacent tissue but is also an important modification of the tumor microenvironment, leading to changes in its regulatory function. When tumors expand, the surrounding stroma undergoes constant remodeling and since collagen is the major component of the extracellular matrix, collagen synthesis and degradation is a key determinant for cancer invasion. However, collagen turnover is not only central for tumor invasion but is also a normal process in the healthy organism, occurring continuously at sites with tissue remodeling. This process is widespread in the body but occurs at highly different rates. For example, cartilage and tendons are characterized by a very slow rate of collagen turnover with a suggested half-life of over 100 years for cartilage $(1,2)$, compared to the considerably accelerated rate in periodontal ligaments with a half-life of 3-23 days $(3,4)$.

The most thoroughly characterized pathway of collagen turnover is the proteolytic breakdown process occurring in the extracellular space. The distinctive triple-helix structure and the ability to form large insoluble fibers makes collagen 
resistant to most proteases (5). Nevertheless, a few specialized collagenases in the matrix metalloprotease family, including MMPs -1, -2, -8, -13-16, and the cysteine protease cathepsin K, are able to perform a proteolytic attack on the rigid structure (6-8). The degradation process is initiated by the unwinding of collagen fibers which exposes cleavage sites targeted by these specialized proteases. Their activity produces well-defined $1 / 4$ and $3 / 4$ collagen fragments, which are subsequently cleared by other proteases. However, in addition to this well established extracellular breakdown pathway, a less characterized intracellular process in which collagen is internalized through binding to collagen-specific receptors on the cell surface and delivered for lysosomal degradation has also been identified. In 2000, two studies reported the cloning of uPARAP/Endo180, a type-1 membrane protein belonging to the mannose receptor family $(9,10)$ which later turned out to be responsible for this process. This receptor, also referred to as CD280 (11), is the product of the MRC2 gene, situated on chromosome 17q23 in humans (link to gene information: http://www.ncbi.nlm.nih. gov/gene? $\mathrm{Db}=$ gene $\& \mathrm{Cmd}=$ DetailsSearch $\&$ Term=9902; human gene).

In this review, we summarize the features and function of UPARAP/Endo180 and discuss the putative role of this collagen receptor in various cancers and other diseases characterized by dysregulation of collagen remodeling.

\section{2. uPARAP/Endo180: an endocytic receptor for collagen}

The collagen binding function of uPARAP/Endo180 was initially demonstrated in ligand competition experiments during the characterization of the receptor on cultured cells (9). Studies with wild-type cells and cells from uPARAP/ Endo180-deficient mice, as well as cells transfected with uPARAP/Endo180 cDNA in vitro, revealed that this binding is associated with an active endocytosis machinery and that the receptor functions in collagen internalization (12-14). Thus, the bound collagen is routed through clathrin coated pits to the endosomal/lysosomal compartment (13) where collagen degradation occurs in a process dependent on cysteine proteases (15). This routing of the bound ligand is governed by a short sequence motif in the small cytoplasmic domain of the receptor (Fig. 1) (16). The receptor is recycled back to the cell surface from the early endosomal compartment (16).

A complete survey of collagen subtypes has not been undertaken. However, the evidence obtained so far makes it likely that the binding and internalization capacity of uPARAP/Endo180 comprises most or all structural collagens. Positive binding and/or internalization data have been obtained for at least fibrillary collagens I, II and V and for sheet-like (basement membrane-type) collagen IV $(12,13)$. Although it should be noted that additional roles of this receptor have also been studied in vitro, particularly in relation to cell migration $(17,18)$, the discussion in this review will be focused on the function in collagen turnover.

Important preferences exist regarding the physical form of the internalized collagen. In the majority of studies on uPARAP/Endo180 and collagen, internalization has been demonstrated with solubilized collagens subjected to various means of labeling, meaning that the conformational state of the material is not known in detail. Furthermore, it is not completely clear what would be the physical size limit for collagen units or fragment to allow cell entry through internalization by this receptor. Studies in a mouse mammary tumor model showed the uptake of collagen to occur exclusively in uPARAP/Endo180-positive, fibroblast-like cells, with at least some of the internalized material having a fibril-like appearance as judged by electron microscopy (19). On the other hand, most studies so far have counted against a function of uPARAP/Endo180 in regular phagocytosis (16), thus pointing to stringent size constraints for material to be internalized by this receptor.

Whereas the internalization of strictly native collagen fibrils is not easily quantified under controlled conditions, a stringent pattern can be achieved after manipulation with the collagen structure. Thus, a deliberate (heat-induced) denaturation of collagen leads to increased binding to UPARAP/ Endo180 and increased uptake by cells expressing the receptor (20). This observation is important because a similar denaturation process occurs as a consequence of initial (single-site) proteolytic cleavage of triple helical collagen and indeed, the same study showed that pre-cleaved collagen displays increased binding and uptake, just like the heat-denatured material. In accordance with these findings, studies with fibroblasts on a native (insoluble) collagen matrix showed that the collagenase MT1-MMP on the cell surface is responsible for a pre-cleavage of collagen into defined soluble fragments that are then endocytosed by uPARAP/Endo180 (20). Experiments with cells seeded on a pre-assembled matrix with polymerized collagen I and fibronectin showed that uPARAP/Endo180 was indeed important for efficient cellular uptake of matrix collagen (21). However, these studies also pointed to a complicated interplay between collagen, the fibronectin component, integrins and proteolytic (MMP-catalyzed) processes, in addition to the role uPARAP/Endo180. Since these experiments did not allow a direct evaluation of the single events involved, the molecular form of collagen actually taken up by uPARAP/ Endo180 could not be established with certainty.

Obviously, the role of this receptor must be understood in the context of other collagen-binding proteins. Several cell surface proteins are known to bind to structural collagens, acting in diverse processes of adhesion, migration and signaling (reviewed in ref. 22). However, the majority of these proteins do not take part in endocytic processes such as those described above. It should be noted that a phagocytic collagen uptake mechanism in fibroblasts was noted at an early point (23). However, phagocytic uptake of collagen particles seems to be governed mainly by collagen-binding integrins such as $\alpha 2 \beta 1$ (24), unlike the clathrin-associated endocytosis mediated by uPARAP/Endo180 which is integrin-independent $(12,25)$. The role of the mannose receptor (MR) in collagen endocytosis is described in the following section.

\section{Functional properties of uPARAP/Endo180 and related receptors}

Cloning of the uPARAP/Endo180 cDNA $(9,10,26)$ revealed that the protein is a member of the mannose receptor protein family, a well-characterized group of lectin-like endocytic receptors. This family includes four members in mammals. In addition to uPARAP/Endo180 itself, these are the (macro- 


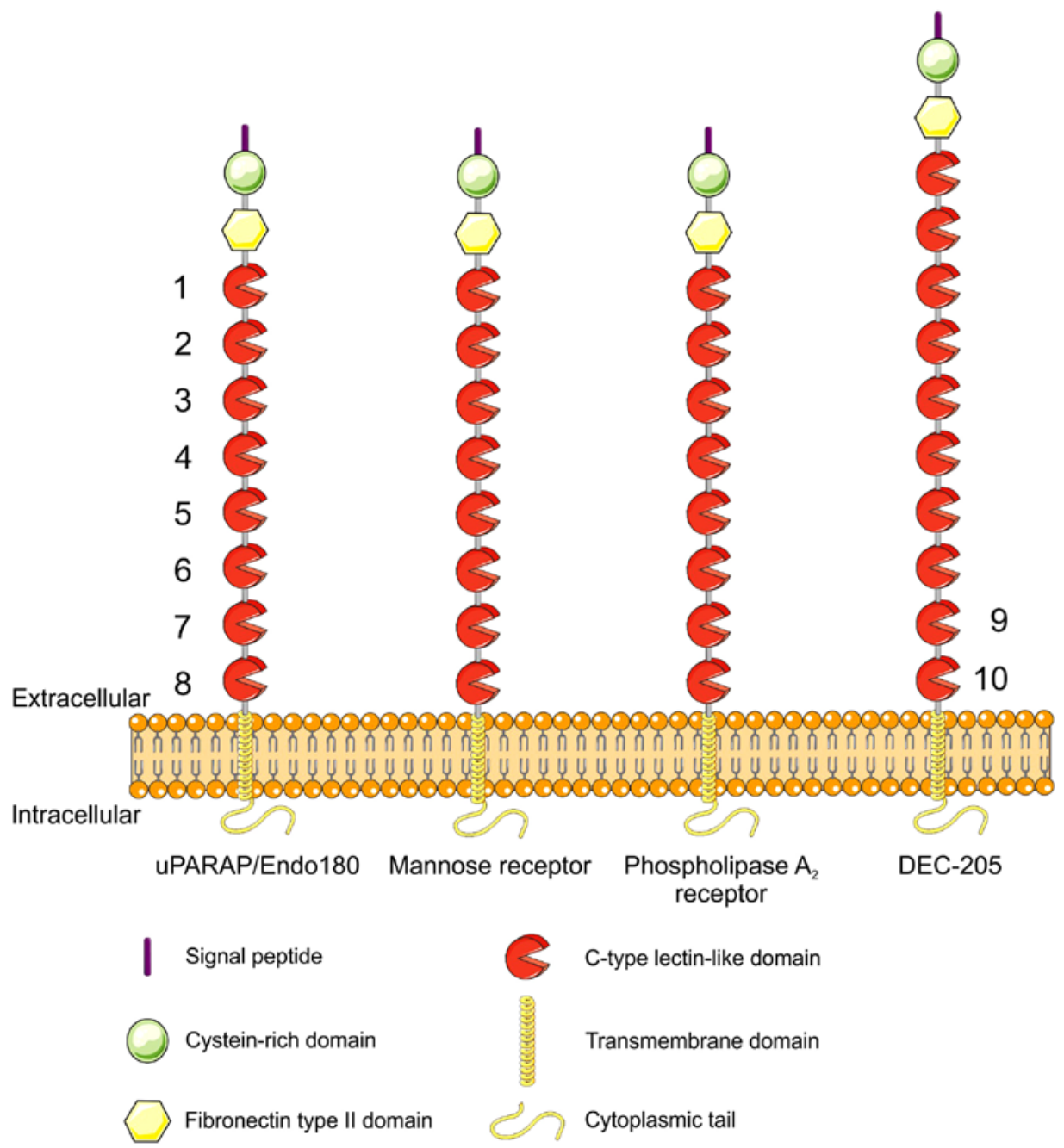

Figure 1. The Mannose receptor family. Schematic representation of the four protein family members. All of the proteins have the same over-all domain composition with an $\mathrm{N}$-terminal signal peptide followed by a cysteine-rich domain, a fibronectin type II domain, 8-10 C-type lectin-like domains, a transmembrane spanning region and a small cytoplasmic tail. During evolution, the two additional carbohydrate recognition domains in DEC-2005 have most likely arisen through a gene duplication of domains 7 and 8 (85). The only family members that have been demonstrated to mediate collagen endocytosis are uPARAP/ Endo180 and the mannose receptor (MR) (34).

phage) mannose receptor (MR), the M-type phospholipase A2 receptor (PLA2R) and the dendritic cell receptor DEC-205. The avian immunoglobulin Y receptor is a bird homologue of PLA2R $(27,28)$.

All of these receptors share a characteristic domain composition (29) (Fig. 1). They are type-1 membrane proteins which, from the $\mathrm{N}$-terminus, are composed of a cysteine-rich (Cys-rich, Ricin B-like) domain, a fibronectin type-II (Fn-II) domain, a series of 8-10 C-type lectin-like domains (CTLDs), a transmembrane segment and a small cytoplasmic domain.

The high degree of conservation of the domain structure, including the presence of a fibronectin type-II domain in all of the receptor family members (29), has prompted the investigation of any collagen-binding function in the other members of the family. It was soon realized that MR itself also has the capacity to bind and internalize collagen $(30,31)$, most likely in a manner very similar to that of uPARAP/Endo180, although these receptors are mostly expressed on different cell types. Indeed, the expression of MR on liver sinusoidal endothelial cells is responsible for hepatic clearance of injected, solubi- lized collagen (32) whereas MR on M2-like macrophages was shown to be active in the endocytosis of fluorescence-labeled collagen that was polymerized after injection under the skin of mice in vivo (33). A recent systematic study with transfected cells confirmed that uPARAP/Endo180 and MR both possess the capacity for collagen endocytosis but also showed that PLA2R and DEC-205 have no such capacity (34). It should be noted that this notion contradicts an early study, pointing to some degree of collagen binding in PLA2R (35) and to a recent study which led to the same conclusion although the difference between mock-transfected and PLA2Rtransfected cells was rather small (36). The background for this discrepancy remains to be determined. It is possible that some species-specific difference exists in this interaction as suggested in the last-mentioned study, or that PLA2R possesses an activity which is just much smaller than that of uPARAP/Endo180 and MR. Altogether, based on the direct comparison presented in the report (34), it is our interpretation that uPARAP/Endo180 and MR are the two dominant collagen receptors in this family. 
As would be expected from the evidence obtained from several other collagen-binding proteins, the Fn-II domain of uPARAP/Endo180 plays a decisive role in collagen binding. Although the Fn-II domain does not appear to obtain the correct native protein folding when expressed alone, stable truncated versions of uPARAP/Endo180 can indeed be obtained which comprise the Fn-II domain with its two flanking domains (i.e., constructs representing the first three $\mathrm{N}$-terminal domains of the receptor; Fig. 1). These protein constructs retain collagen binding $(13,37)$. Even more clearly, the importance of the Fn-II domain has been shown by mutagenesis studies, using cells transfected to express full-length receptor variants (34). These studies have shown, firstly, that the Fn-II domain of uPARAP/Endo180 can be interchanged with that from MR to still allow collagen internalization, whereas an interchange with Fn-II domains from PLA2R or DEC-205 leads to loss of this capability. Secondly, a 10-amino acid loop within the Fn-II domain of UPARAP was found to be crucial for collagen binding and uptake.

An additional domain in uPARAP/Endo180 with functional importance is the second lectin-like domain (CTLD-2). Although the receptor structure includes eight domains classified as CTLDs on the basis of sequence homology, it appears that only CTLD-2 has an active lectin function (38). This capacity to bind carbohydrate plays a role in the binding of glycosylated collagen types to the receptor. Whereas the major fibrillar collagen, collagen I, is largely devoid of glycosylation, the sheetlike collagen IV of the basement membrane is more heavily glycosylated (39). It turns out that the binding of collagen IV to uPARAP/Endo180, while still dependent on the Fn-II domain, is modulated by the lectin function of CTLD-2. Conversely, in accordance with the collagen glycosylation difference, CTLD-2 does not seem to be involved in the binding of collagen I (37).

In addition to the direct binding contributions of individual domains, it has been suggested that dynamic properties of the inter-domain organization could be important for the functional properties of this receptor. Thus, studies by singleparticle electron microscopy have pointed to $\mathrm{pH}$-dependent changes in the steric arrangement of the domains. At neutral $\mathrm{pH}$, the protein seems to adopt a 'bent' conformation with the Fn-II domain contacting CTLD-2 (40) whereas, at low $\mathrm{pH}$, it takes up a more open structure (41). Since the receptor binds its ligand at the neutral $\mathrm{pH}$ conditions in the extracellular environment while dissociation occurs in endosomal compartments at low-pH, this conformational change may be important in relation to ligand binding and release (42).

\section{Role of uPARAP/Endo180 in the healthy organism}

Gene knock-out studies $(12,14)$ have shown that uPARAP-deficient mice are born in the expected Mendelian ratio, are viable and fertile, have normal survival and that they phenotypically appear relatively normal, although they display an effect on bone growth as detailed in the following section. Even though the similar molecular function of uPARAP/Endo180 and MR may suggest a redundant function of these two receptors, mice with double deficiency for these two receptors likewise show no obvious phenotypic abnormality (43).

uPARAP/Endo180 is highly expressed in osteogenic tissue, and a number of reports have demonstrated a role for this collagen receptor in bone development and homeostasis. Perhaps the most striking evidence in this connection came from an independent study investigating a hereditary cattle disease known as the crooked tail syndrome (CTS). Animals suffering from CTS display severe abnormalities in bone development. Following the genetics in a particular strain of cattle and fine mapping of a locus associated with the disease, a 2-bp deletion in the open reading frame of the $M R C 2$ gene coding for uPARAP/Endo180 was identified as the causative mutation (44). A second uPARAP/Endo180 mutation, likewise associated with this disease, was found in a later study (45). In mice, the consequence of uPARAP/Endo180 deficiency is less pronounced than that noted in cattle. However, uPARAP/ Endo180 knock-out mice show a small but significant reduction in the length of the long bones, both in newborn and adult mice $(46,47)$ and a reduced bone mineral density in adult mice. Interestingly, the bone defect is strongly augmented when uPARAP/Endo180 deficiency is combined with deficiency for the collagenolytic protease, MT1-MMP (46). An increased effect on the growth retardation of the long bones is also noted in UPARAP/Endo180 - MMP-2 double deficient mice (47). However, in this case the augmentation is less pronounced than that seen in mice with combined uPARAP/Endo180 and MT1-MMP deficiency and an additional difference is noted when comparing different bone compartments. Thus, opposite to MT1-MMP-deficient mice, the lack of MMP-2 leads to an increase in the thickness of the calvarium $(48,49)$. This effect is counteracted after combination with uPARAP/Endo180 deficiency, demonstrating that uPARAP/Endo180 and MMP-2 do not in all cases support the same degradative processes (47). Studies in vitro have also contributed to understanding the role of uPARAP/Endo180 in bone homeostasis particularly in the context of the coupling between bone formation and resorption. Throughout life, bone is maintained by a remodeling system consisting of continuous bone resorption by osteoclasts followed by bone formation by the osteoblasts. Recently, it was suggested that uPARAP/Endo180 contributes to this process since migration of osteoblast progenitors into resorption pits created by osteoclasts appeared to be driven to some extent by interactions between residual collagen fragments, left behind by the osteoclasts, and the uPARAP/Endo180 receptor on osteoprogenitors (50).

So far, deficiency for uPARAP/Endo180 has not been reported in humans. However, a human polymorphism in the MRC2 gene, in the form of a synonymous SNP in exon 30, has been associated with the rate of recurrence after initially curative treatment of patients with early-stage head and neck squamous cell carcinoma (51). Furthermore, an SNP in an MRC2 intron, suggested to be situated in a regulatory region, was found to be associated with degenerative bony changes of the temporomandibular joint (52).

\section{Tissue expression and regulation}

In the healthy organism, uPARAP/Endo180 is primarily expressed by mesenchymal cells such as fibroblasts and osteogenic cells and it is present in sites showing active tissue remodeling, notably including developing bone $(46,47,53)$. This is in line with a comparative study performed on a number of cultured cell lines which also pointed to a clear preference for 

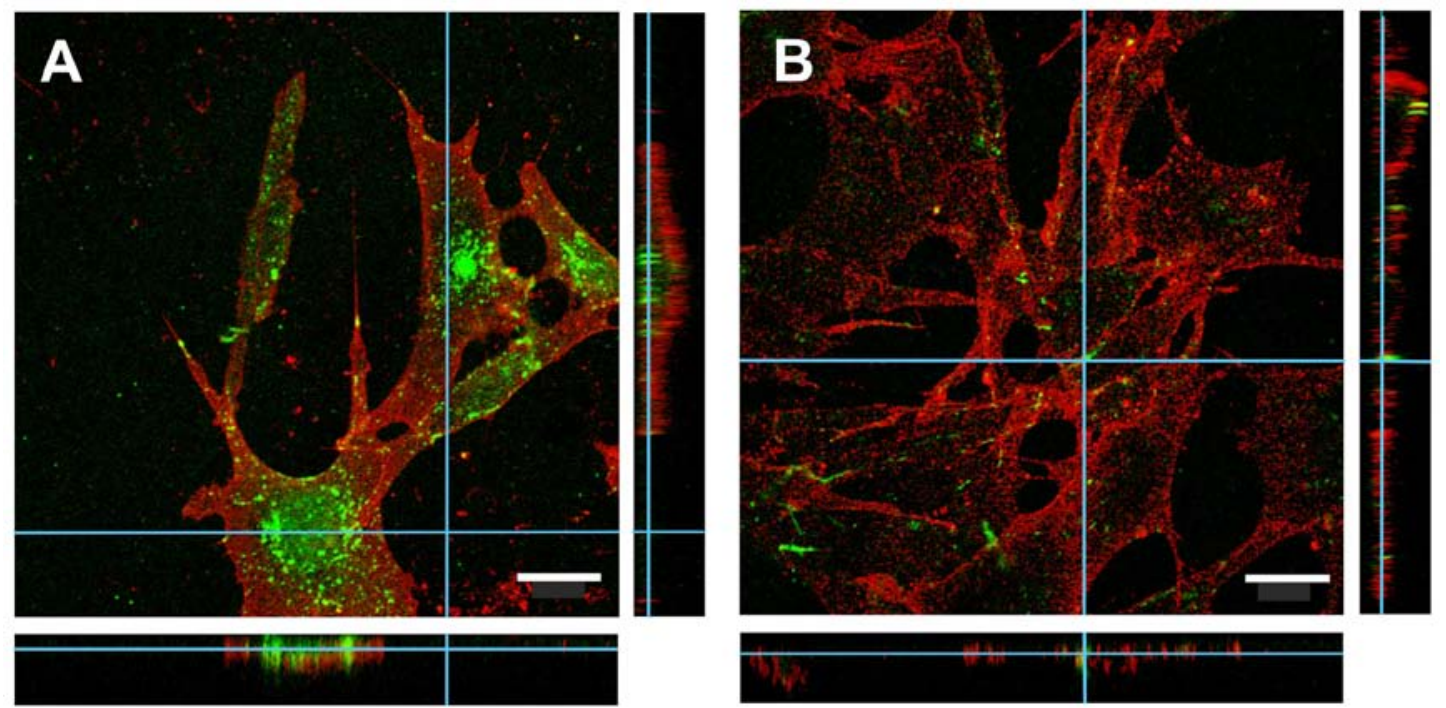

Figure 2. uPARAP/Endo180-mediated collagen endocytosis. Analysis of collagen uptake in: (A) wild-type and (B) uPARAP/Endo180 deficient mouse fibroblasts using confocal microscopy. Live cells were incubated with OG-collagen IV (green) to allow endocytosis, followed by fixation and cell surface staining (red). The punctuated green staining pattern indicates localization of intracellular collagen in endosomal/lysosomal compartments. Scale bar, $20 \mu \mathrm{m}$. Figure was adapted from (15).

mesenchymal expression (25). uPARAP/Endo180 is localized in membrane-associated clathrin-coated pits or intracellular endosomes and is a constitutively rapidly recycling receptor. In fact, at any given time the largest pool (70-90\%) of uPARAP/ Endo180 can be found in intracellular cell compartments $(16,54)$. Indeed, when staining for uPARAP/Endo180 by immunohistochemistry, the characteristic punctuated staining pattern is a reflection of its localization in membrane-associated pits and endosomal compartments (Figs. 2 and 5).

In the murine embryo, uPARAP/Endo180 is expressed in all tissues undergoing primary ossification, both through the intramembranous and the endochondral pathway, and the cells expressing uPARAP/Endo180 in these tissues are of osteoblast linage $(26,53)$. The same expression pattern can be seen in young mice where uPARAP/Endo180 is found on osteoblasts/ osteocytes but also on chondrocytes $(46,55)$, although it has been suggested that the expression by chondrocytes declines with age (55).

In accordance with the strong prevalence of uPARAP/ Endo180 in bone tissue of murine embryos and young mice, the calvaria and tibia are among the organs with the highest level of uPARAP/Endo180 expression also in adult mice (47). When investigating the expression pattern in adult bone tissue in more detail by immunohistochemistry, it was demonstrated that the UPARAP/Endo180-positive cells are the same as in young mice, i.e., osteoblastic lineage cells (47). A strong expression of the receptor in humans and mice was seen on the so-called bone lining cells which form a sheet covering the bone surface $(47,50)$ (Fig. 3). These cells are thought to be important for bone remodeling (56) and therefore it seems that uPARAP/Endo180 is important not only for bone generation, but also for bone homeostasis.

In addition to the bone compartment, uPARAP/Endo180 is expressed in several organs and tissues. In adult mice, the receptor has been demonstrated in a wide range of organs with particularly high levels in the uterus and lung $(47,57)$ but

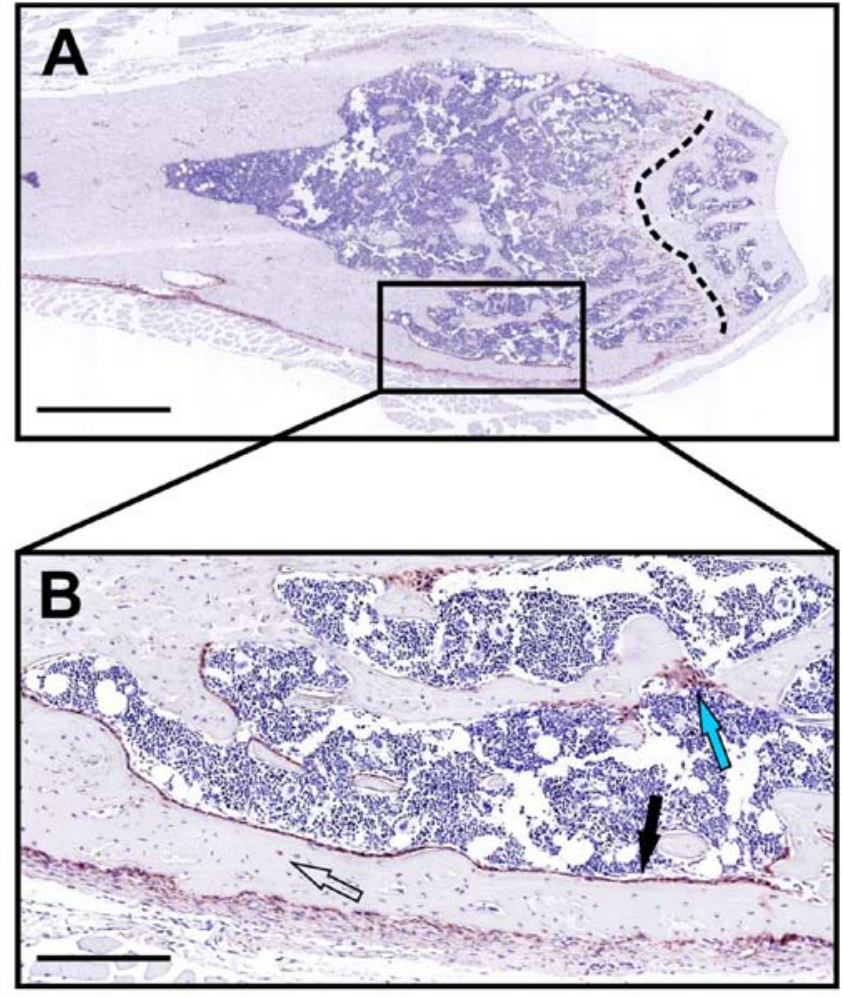

Figure 3. uPARAP/Endo180 expression in murine bone. Mouse femurs were immunostained with antibodies against uPARAP/Endo180 $(78,79)$ (A) Overview showing the upper part of the femur. uPARAP/Endo180 staining is especially prominent in the primary spongiosa (dotted line). (B) Magnification of the area indicated in (A). Expression of uPARAP/Endo180 is observed in the layer of osteoblastic bone lining cells covering the bone surface (black arrow), in osteogenic cells (blue arrow) and in occasional osteocytes (open arrow). Scale bars, $1 \mathrm{~mm}$ (A) and $250 \mu \mathrm{m}$ (B).

with very low levels in liver, muscle and brain (47). In human tissue, one of the first screenings performed by northern blotting revealed high levels of uPARAP/Endo180 expres- 


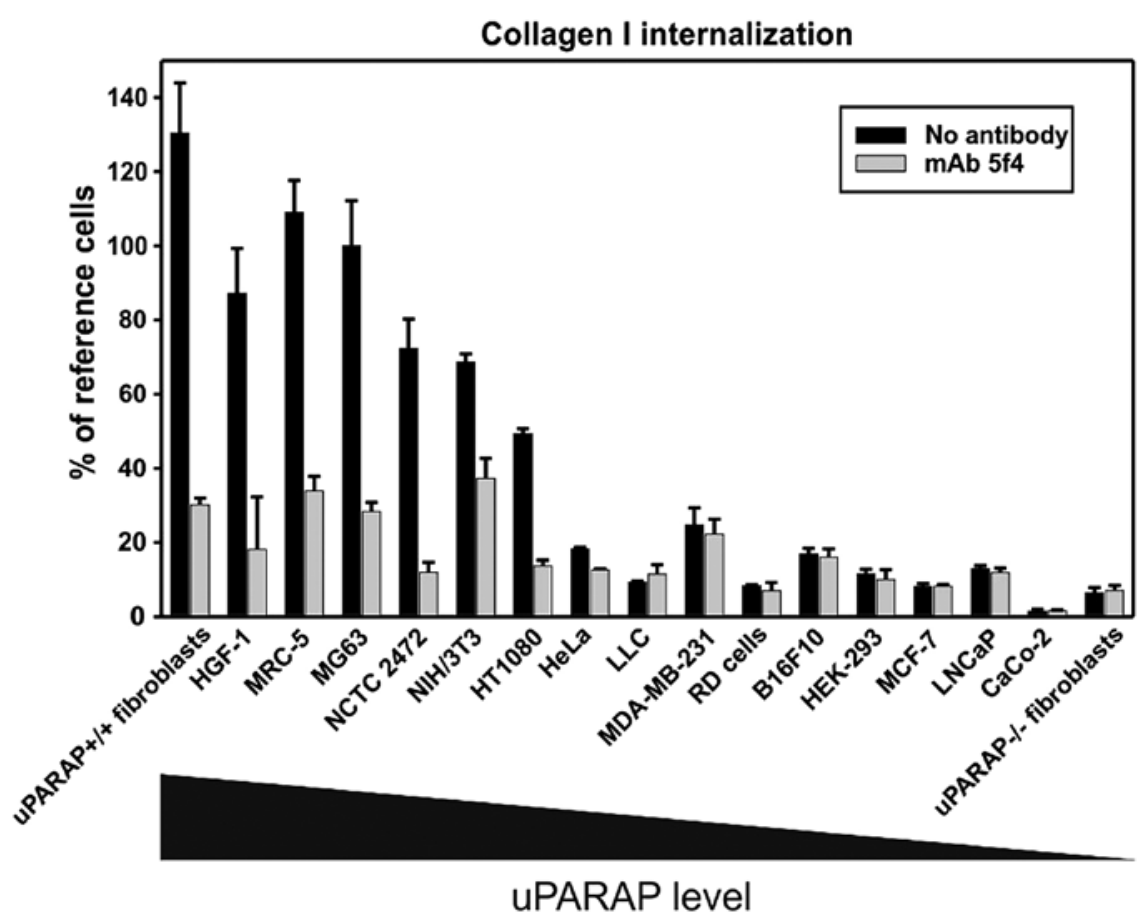

Figure 4. uPARAP/Endo180 expression correlates with cellular ability to internalize collagen. A broad selection of cultured cell lines were assayed for collagen endocytosis in the absence (black columns) or presence (grey columns) of a blocking uPARAP/Endo180 antibody. The cell types analyzed have different expression of uPARAP/Endo180, shown in descending order from left to right. collagen internalization was normalized against a reference cell line (MG63). Figure was adapted from (25).

sion in the heart, prostate, testis, ovary, and intestine, with lower levels in brain, placenta, lung, kidney, pancreas, spleen, thymus and colon (26). Additional studies have reported uPARAP/Endo180 to be present on monocyte-derived skin macrophages (10), although the marker used (CD14) might make it difficult to distinguish between different cell types belonging to the monocyte lineage. Furthermore, the receptor has been observed on human placental cells although there is some discrepancy regarding their lineage, where one report suggested endothelial cells in a subset of microvascular vessels (10) and another mesenchymal cells in the villous stroma (58). A complicated expression pattern, including several cell types, has been reported in human gingival epithelium (59); see further details below.

UPARAP/Endo180 has been shown to be expressed by a large panel of cultured cell lines, primarily of mesenchymal origin, and the level of expression has been shown to correlate with the ability to internalize collagen (25) (Fig. 4). Studies in vitro also suggest that the regulation of this receptor is correlated with the cellular activity in collagen metabolism. Thus, in isolated rat hepatic stellate cells, uPARAP/Endo180 was upregulated as a result of activation and transdifferentiation into a more myofibroblast-like morphology. This correlated with an increased ability to internalize collagen $(60,61)$. A similar pattern in acquiring uPARAP/Endo180 expression and collagen internalization was seen using in vitro differentiated pancreatic stellate cell lines (62). The same study showed that addition of TGF- $\beta$ to induce an EMT-like process in the pancreatic cancer cell lines enhanced uPARAP/Endo180 expression and collagen internalization (62).

In other cell types, in vitro studies on the regulation of uPARAP/Endo180 expression have likewise been focused primarily on the role of TGF- $\beta$. For example, treatment of the breast cancer cell line MCF-7, the U87MG glioma cell line and two prostate cancer cell lines with TGF- $\beta$ resulted in upregulation of the collagen receptor (63-65) and the same was observed when using human gingival fibroblasts where both uPARAP/Endo180 protein expression and mRNA levels increased in the presence of TGF- $\beta$ (59). However, one report has shown the opposite effect where uPARAP/Endo180 RNA expression actually decreased in lung fibroblasts following TGF- $\beta$ treatment (57). This difference between fibroblast reaction to TGF- $\beta$ may reflect a difference in tissue remodeling potential depending on their origin and tissue surroundings.

\section{6. uPARAP/Endo180 in breast and prostate cancer}

Early studies on the expression of uPARAP/Endo180 in breast cancer and premalignant conditions showed the receptor to be absent on tumor cells but strongly expressed by the tumorassociated fibroblast-like cells in invasive breast carcinomas and to a limited extent by myoepithelial cells in benign lesions and ductal carcinoma in situ (66). Later studies showed a similar, restrictive expression pattern in the polyomavirus middle T-induced mammary tumor model in mice where uPARAP/Endo180 was found to be present on periductal fibroblast-like mesenchymal cells whereas the mammary epithelial cells and tumor cells were negative (19) (Fig. 5). Moreover, by combining uPARAP/Endo180 gene deficiency with this model, it was found that mice developed less tumor burden and increased collagen accumulation in the tumors as a result of defective collagen clearance by tumor-associated stromal cells (19). These studies pinpointed uPARAP/Endo180 as a stromal contributor to mammary tumor progression. However, 

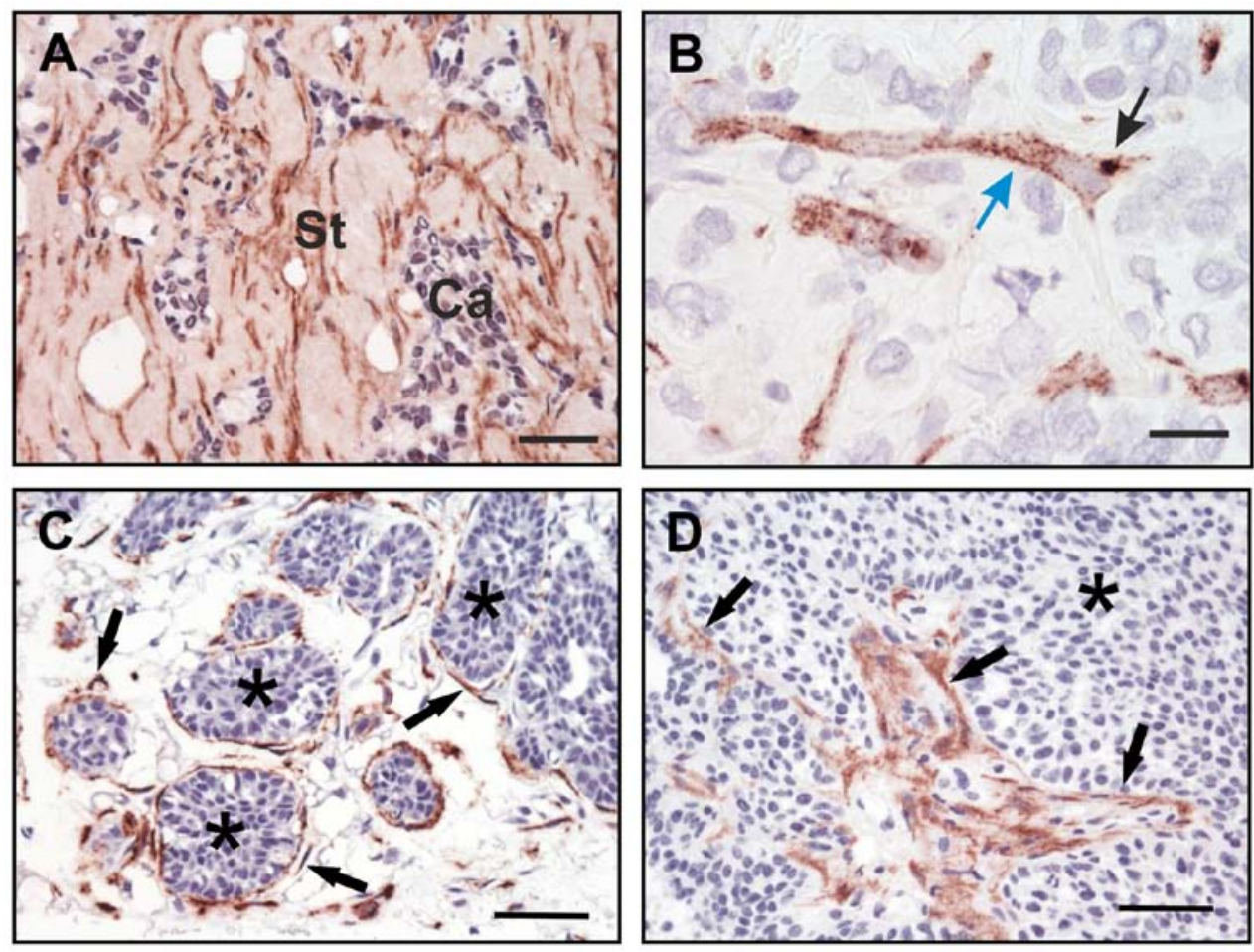

Figure 5. uPARAP/Endo180 expression in malignant breast tumors. Invasive ductal (A) and lobular (B) human breast carcinomas and murine PyMT mammary tumors (C and D) were immunostained using uPARAP/Endo180 specific antibodies against human and mouse uPARAP/Endo180, respectively. (A and B) Expression of uPARAP/Endo180 is only detected in stromal cells (St) whereas the cancer cells $(\mathrm{Ca})$ are negative. The punctuated perinuclear (B, black arrow) and granulated cytoplasmic (B, blue arrow) staining pattern is indicative of the localization of uPARAP/Endo180 in intracellular vesicular compartments, including endosomes. Scale bars, $50 \mu \mathrm{m}$ (A) and $25 \mu \mathrm{m}$ (B). (C and D) uPARAP/Endo180 expression in: (C) mammary intraepithelial neoplasia of a 5-week-old female PymT mouse and (D) advanced mammary carcinoma in a 13-week-old female PymT mouse. As in human breast tumors, uPARAP/Endo180 is expressed in stromal fibroblast-like mesenchymal cells (arrows), but absent in mammary tumor cells (asterisks). Scale bars, $50 \mu \mathrm{m}$ (C and D). (A and B) were adapted from (66); (C and D) adapted from (19).
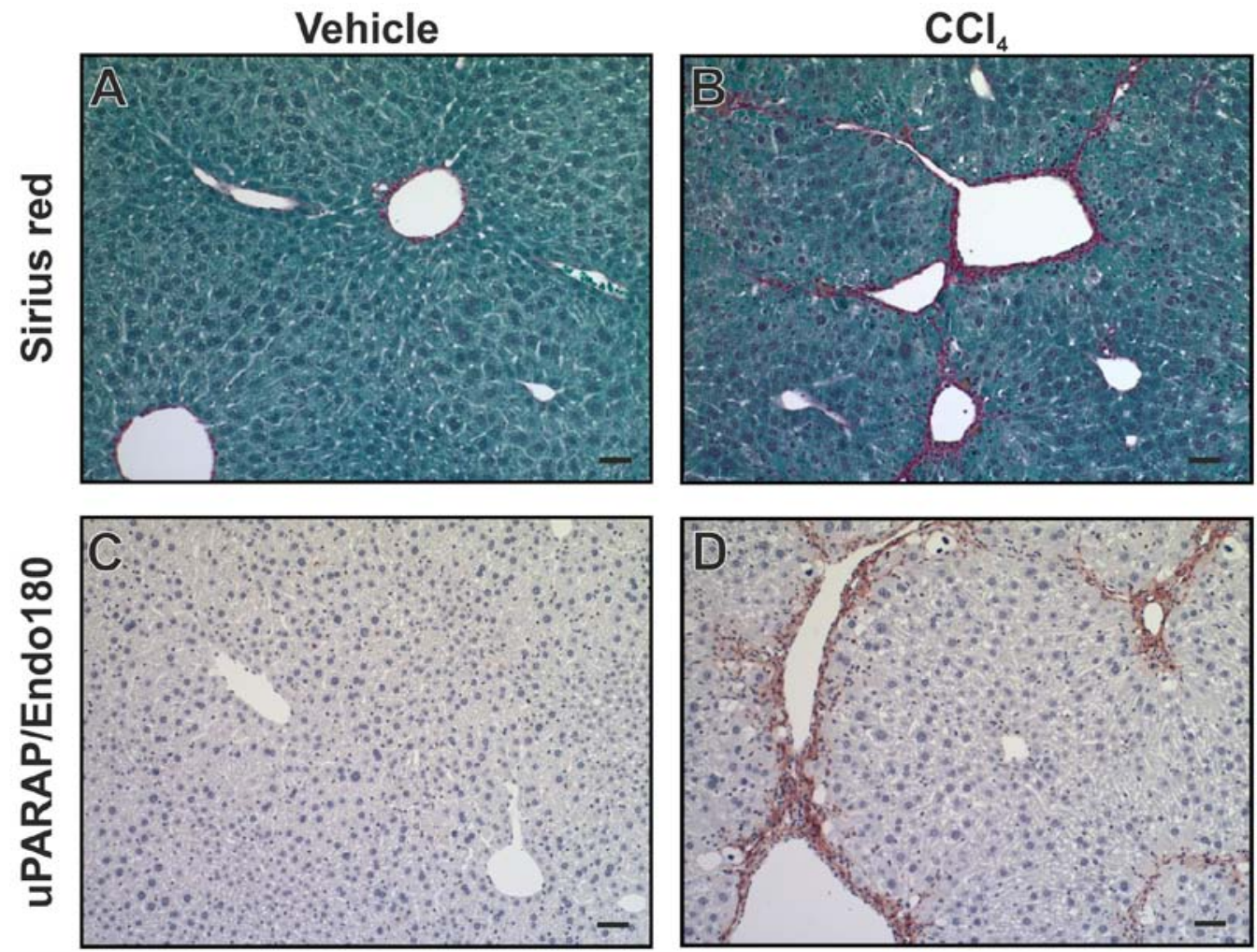

Figure 6. Upregulation of uPARAP/Endo180 in a mouse model of liver fibrosis. Mice were treated with vehicle (A and C) or with CCl ${ }_{4}$ for 6 weeks (B and D) to induce liver fibrosis. Livers from these mice were then stained for uPARAP/Endo180 (78) or for fibrillar collagen with picrosirius red with fast green as counterstaining. The expression of uPARAP/Endo180 is seen in cells associated with fibrillar collagen accumulation and in the periportal sinusoids. Scale bars, $50 \mu \mathrm{m}$. Figure was adapted from (79). 
studies on a large number of human breast cancers revealed a small subset (3-6\%) of breast tumors in which the tumor cells were uPARAP/Endo180-positive (63). These samples belonged to a hormone triple-negative subtype of breast carcinomas with basal- (myoepithelium-) like characteristics. It was hypothesized that, in some tumors, tumor cells might acquire UPARAP/Endo180 expression, e.g., after stimulation with TGF- $\beta$, and that this might play a role in invasive tumor growth. When human MCF-7 breast tumor cells, which are initially uPARAP/Endo180 negative, were transfected to express this receptor and grown in nude mice, they displayed increased tumor growth and enhanced collagen turn-over, relative to mock-transfected cells (63). A recent study has proposed uPARAP/Endo180 as a potential marker for metastatic breast cancer. In this report, uPARAP/Endo180 immunoreactivity was observed in patient plasma samples, ascribed to protein shedding. Quantification of immunoreactivity by western blotting indicated higher levels of uPARAP/Endo180 in recurrent (metastatic) breast cancer patients as compared with patients with early (localized) breast cancer (67).

The expression and the possible prognostic significance of UPARAP/Endo180 has also been studied in prostate cancer (68-70). It was found that uPARAP/Endo180 was increasingly expressed in clinical high-risk group tumors and that the expression was negatively correlated with survival. The receptor was reported to be expressed in stromal as well as tumor cells, although the use of tissue microarray (TMA) material in the major part of these studies makes it difficult to quantitatively evaluate the cellular composition of these samples.

\section{7. uPARAP/Endo180 in glioma}

Glioma originates from the glial cells in the brain and accounts for about a third of all primary brain cancers. It is divided into four main types where glioblastoma multiforme (GBM) has the worst prognosis with a median survival of 15 months despite aggressive treatment (71). The tumors are highly invasive, probably being caused in part by the increased interaction and degradation of the ECM which promotes migration of the tumor cells (72). The collagen content in the brain mainly consists of collagen IV, which is found on basement membrane surrounding vascular endothelial cells. Although there are limited amounts of collagen in the normal brain, this type of collagen, together with other ECM components such as laminin and fibronectin, is upregulated in gliomas due to increased microvasculature (73). Additionally, it has been shown that fibrillary collagen type I is deposited within GBM tumors (65). Interestingly, in an in silico analysis of available gene expression data, uPARAP/Endo180 was shown to be highly upregulated in glioblastomas (grade IV) compared to lower grade gliomas (grade II) (65). Upregulation of uPARAP/ Endo180 was also seen in a different study where the results were based on a QT-PCR analysis on a cDNA panel from normal and GBM brain tissue (74). These findings have been confirmed at the protein level by immunohistochemistry in both whole tissue and tissue micro arrays where $80-100 \%$ of GBM samples analysed were positive for uPARAP/Endo180 (65). Also, in agreement with previous studies, suggesting a preference for UPARAP/Endo180 expression on cells of mesenchymal origin, uPARAP/Endo180 was found to be more associated with the mesenchymal subclass of high-grade gliomas compared to proneural and proliferative subgroups (65).

The expression and function of uPARAP/Endo180 has also been investigated in glioma cell lines. The receptor is expressed by several glioma-derived cell lines and downregulation of uPARAP/Endo180 expression has been shown to reduce their migratory and collagen-invasive capacity in vitro, suggesting an active participation of UPARAP/Endo180 in glioma cell invasion $(65,74)$. Therefore, considering the low expression level of uPARAP/Endo180 in normal brain tissue, the fact that it is highly upregulated in GBM and appears to have a role in tumor cell migration makes it a promising therapeutic target.

\section{8. uPARAP/Endo180 in bone cancer}

The most common bone cancers occur as the result of metastatic spread from tumors in other organs, such as breast, lung or prostate carcinomas. When metastatic tumor cells spread to the bones and form secondary tumors, the result on the bone matrix is often a shift in bone homeostasis favoring bone degradation. This is hypothesized to be due to a secondary effect of tumor cell growth through increased osteoclast activity. The model is termed the 'vicious cycle' whereby tumor cells, through release of cytokines and growth factors activate osteoblasts which in turn secrete an osteoclast activating factor known as RANKL. Increased activity of the osteoclasts result in release of calcium and growth factors from the bone matrix which in turn stimulate tumor growth, thus augmenting the cycle (75). The role of uPARAP/Endo180 in this setting is not clear but one study has reported that upon co-culture with osteoblasts, uPARAP/Endo180 was upregulated on prostate cancer cell lines while simultaneously expression on osteoblasts was found to decrease (64). In this cell culture system, uPARAP/Endo180 expression on osteoblasts facilitated deposition of collagen type I rather than degradation but the co-culture with tumor cells suppressed this function. Further studies on the co-culture system pointed to a dysregulated TGF $\beta 1$ signaling being responsible for these regulatory events (64). Another link between uPARAP/ Endo180 and metastatic bone cancer was found in the abovementioned study on uPARAP/Endo180 in the plasma of breast cancer patients, where the metastatic group included patients with bone metastases (67).

\section{UPARAP/Endo180 in other cancers}

An early report, focused on endothelial gene products preferentially expressed in tumors, employed differential gene expression analysis with isolated endothelial cell material from malignant versus normal colorectal tissue. This study identified uPARAP/Endo180 among the 25 mostly elevated transcripts in the tumor vessels (76). However, although considerable care was taken to obtain pure cell populations for comparison in this study, it is difficult to judge whether this is actually a proof of endothelial upregulation because most subsequent studies on cancer-associated expression of this receptor have led to receptor identification on cell types other than the endothelium 
(see above). An upregulation of uPARAP/Endo180 has been shown in hepatocellular carcinoma where a higher expression of the receptor was correlated with a poor prognosis (77). In addition, an upregulation of the receptor has been observed in the stromal compartment of several types of head-and-neck cancers, relative to the surrounding tissue (78). Furthermore, in this study expression was found to be most prominent in poorly differentiated tumors.

\section{Expression and role of UPARAP/Endo180 in other pathological conditions}

Since uPARAP/Endo180 is involved in events related to collagen remodeling, there has been a clear rationale to investigate its influence in disorders characterized by dysfunctional collagen turnover. Fibrosis can occur in several organs in the body and includes a buildup of connective tissue matrix, primarily collagen, in response to tissue damage or due to an underlying genetic defect. In human liver cirrhosis, i.e., the end-stage of liver fibrosis, a strong, localized upregulation of uPARAP/ Endo180 was observed in fibroblast-like cells (79). Using a mouse model for liver fibrosis, induced by injection of $\mathrm{CCl}_{4}$, a similar upregulation was observed (Fig. 6). Furthermore, when UPARAP/Endo180-deficient mice were studied using the same model, fibrosis was worsened with increased collagen accumulation, relative to littermate wild-type mice (79). This points to a protective role of UPARAP/Endo180 in this condition, completely in line with the function in collagen clearance. Chronic kidney disease (CKD) is caused in part by defective tissue remodeling of the tubules resulting in accumulation of interstitial collagens. In a mouse model for CKD, induced by unilateral ureteral obstruction, uPARAP/ Endo180 deficiency was shown to give rise to aggravated renal fibrosis with increased collagen content and reduced collagen turnover (80), suggesting a function of the receptor similar to that found in liver fibrosis. The role of UPARAP/Endo180 in lung fibrosis has also been studied. Using a mouse model for lung fibrosis induced by bleomycin, a decrease in uPARAP/ Endo180 expression following bleomycin administration was demonstrated. When challenging uPARAP/Endo180-deficient mice with bleomycin, the collagen accumulation was larger and the increase in lung permeability was smaller compared to wild-type mice, indicating a role for UPARAP/Endo180 also in matrix remodeling following lung injury (57).

Wound healing and the associated scar formation and subsequent resolution are complicated processes that require an intricate balance between collagen synthesis and degradation. Some tissues, like the mucosal gingiva, have the ability of faster wound healing with less scarring, i.e., less collagen deposition, compared to other tissues, which makes it relevant to study the molecular components involved in collagen turnover in this situation. Thus, the expression of uPARAP/ Endo180 has been studied in biopsies collected from normal and wounded human gingiva (59). In contrast to localization studies in most other tissues, this report pointed to expression of the receptor in a very broad range of cell types, including epithelial cells in addition to several cell populations in the connective tissue, and with an upregulation of expression on the migrating keratinocytes after the wound was made. Although it was suggested that various particular properties of the gingival epithelium may lead to a unique ability to express uPARAP/Endo180 (59), the use of immunofluorescence for detection made it difficult to evaluate the strength of the specific signal obtained in these tissues. During skin wound healing in mice, uPARAP/Endo180 expression was also seen to be upregulated and a delayed response in re-epithelialization was noted in mice deficient for UPARAP/Endo180 (81). However, deficiency for UPARAP/Endo180 did not affect the time course of the macroscopic process of wound closure and there was no difference in collagen content in wounds from wild-type and uPARAP/Endo180-deficient mice. The authors suggested the latter observation to reflect that other, compensatory mechanisms are in play in the skin (81).

Collagen is also abundant in human skin and during UV-induced aging of the skin, also known as photoaging, collagen integrity is lost. In more severe cases, photoaging can lead to development of actinic keratoses and ultimately squamous cell carcinoma (82). By comparing sun-exposed and sun-protected areas of the skin from patients diagnosed with early photoaging, it was demonstrated that uPARAP/Endo180 was downregulated in the sun-damaged skin areas and that collagen fragments were accumulated in the same locations (83). Although this result was based on a comparison of skin surfaces from different parts of the body, the same study also demonstrated an acute downregulation of uPARAP/Endo180 after experimental, short-term UV-irradiation of human skin. Furthermore, using an in vitro approach it was demonstrated that UV-exposed human dermal fibroblasts had a reduced expression of uPARAP/Endo180, as well as a reduced capacity for collagen internalization (83). A downregulation of uPARAP/ Endo180 by UV-irradiation of human dermal fibroblasts was also seen in another study which, furthermore, demonstrated that the drug all trans retinoic acid (ATRA) could serve to reverse the effect on UPARAP/Endo180 expression (84). The authors suggested that, through this effect, ATRA might be useful in stimulating endocytic collagen internalization which might in turn contribute to reduce the symptoms associated with photoaging.

\section{Conclusions and perspectives}

The discovery of uPARAP/Endo180 as an endocytic collagen receptor has led to the delineation of a novel intracellular pathway of matrix breakdown. This pathway both complements and acts in concert with the well-established function of matrix-degrading extracellular proteases. In spite of the requirement for certain proteolytic events in conjunction with the endocytic mechanism, the action of UPARAP/Endo180 is in some cases rate limiting with respect to extracellular matrix turnover in vivo. This is reflected by phenotypic abnormalities in bone growth upon uPARAP/Endo180 deficiency, by protective functions in conjunction with the excessive build-up of extracellular matrix in fibrosis and by active pathological functions in the matrix breakdown processes associated with cancer invasion. Since inactivation of uPARAP/Endo180 would probably be well tolerated in the adult organism, the degradative function of this receptor makes it an interesting target for anti-invasive cancer therapy and treatment of other degenerative diseases. To pursue this possibility, important questions to be answered will include the details of the 
receptor's expression pattern in various cancers, an improved understanding of its functional redundancy and interplay with other degradation mechanisms and the result of experimental targeting in mouse models. Such studies may open the way for a whole new concept of treatment in matrix degenerative disease.

\section{Acknowledgements}

This study was supported by the Danish Cancer Society, the Danish Medical Research Council, the Danish Cancer Research Foundation, the Lundbeck Foundation, the Novo Nordisk Foundation, the Danish National Research Foundation (Danish-Chinese Center for Proteases and Cancer) and the European Community's Seventh Framework Programme FP7/2007-2011 under grant agreement no. 201279.

\section{References}

1. Maroudas A, Bayliss MT and Venn MF: Further studies on the composition of human femoral head cartilage. Ann Rheum Dis 39: 514-523, 1980

2. Maroudas A, Palla G and Gilav E: Racemization of aspartic acid in human articular cartilage. Connect Tissue Res 28: 161-169, 1992.

3. Ahuja TD, Dhakray V, Mittal M, Khanna P, Yadav B and Jain M Role of collagen in the periodontal ligament (review). Internet $\mathrm{J}$ Microbiol 10: 2012.

4. Sodek J and McKee MD: Molecular and cellular biology of alveolar bone. Periodontol 2000 24: 99-126, 2000

5. Ottani V, Martini D, Franchi M, Ruggeri A and Raspanti M: Hierarchical structures in fibrillar collagens. Micron 33: 587-596, 2002.

6. Saftig P, Hunziker E, Wehmeyer O, Jones S, Boyde A, Rommerskirch W, Moritz JD, Schu P and von Figura K: Impaired osteoclastic bone resorption leads to osteopetrosis in cathepsinK-deficient mice. Proc Natl Acad Sci USA 95: 13453-13458, 1998.

7. Hotary K, Li XY, Allen E, Stevens SL and Weiss SJ: A cancer cell metalloprotease triad regulates the basement membrane transmigration program. Genes Dev 20: 2673-2686, 2006.

8. Shi J, Son MY, Yamada S, Szabova L, Kahan S, Chrysovergis K, Wolf L, Surmak A and Holmbeck K: Membrane-type MMPs enable extracellular matrix permissiveness and mesenchymal cell proliferation during embryogenesis. Dev Biol 313: 196-209, 2008.

9. Behrendt N, Jensen ON, Engelholm LH, Mørtz E, Mann M and Danø K: A urokinase receptor-associated protein with specific collagen binding properties. J Biol Chem 275: 1993-2002, 2000.

10. Sheikh H, Yarwood H, Ashworth A and Isacke CM: Endo180, an endocytic recycling glycoprotein related to the macrophage mannose receptor is expressed on fibroblasts, endothelial cells and macrophages and functions as a lectin receptor. J Cell Sci 113: 1021-1032, 2000

11. Thomas EK, Nakamura M, Wienke D, Isacke CM, Pozzi A and Liang P: Endo180 binds to the C-terminal region of type I collagen. J Biol Chem 280: 22596-22605, 2005.

12. Engelholm LH, List K, Netzel-Arnett S, Cukierman E, Mitola DJ, Aaronson H, Kjøller L, Larsen JK, Yamada KM, Strickland DK et al: uPARAP/Endo180 is essential for cellular uptake of collagen and promotes fibroblast collagen adhesion. J Cell Biol 160: 1009-1015, 2003.

13. Wienke D, MacFadyen JR and Isacke CM: Identification and characterization of the endocytic transmembrane glycoprotein Endo180 as a novel collagen receptor. Mol Biol Cell 14: 3592-3604, 2003.

14. East L, McCarthy A, Wienke D, Sturge J, Ashworth A and Isacke CM: A targeted deletion in the endocytic receptor gene Endo180 results in a defect in collagen uptake. EMBO Rep 4: 710-716, 2003

15. Kjøller L, Engelholm LH, Høyer-Hansen M, Dan $\varnothing$ K, Bugge TH and Behrendt N: uPARAP/endo180 directs lysosomal delivery and degradation of collagen IV. Exp Cell Res 293: 106-116, 2004.
16. Howard MJ and Isacke CM: The C-type lectin receptor Endo180 displays internalization and recycling properties distinct from other members of the mannose receptor family. J Biol Chem 277: 32320-32331, 2002.

17. Sturge J, Wienke D, East L, Jones GE and Isacke CM: GPI-anchored uPAR requires Endo180 for rapid directional sensing during chemotaxis. J Cell Biol 162: 789-794, 2003.

18. Sturge J, Wienke D and Isacke CM: Endosomes generate localized Rho-ROCK-MLC2-based contractile signals via Endo180 to promote adhesion disassembly. J Cell Biol 175: 337-347, 2006.

19. Curino AC, Engelholm LH, Yamada SS, Holmbeck K, Lund LR, Molinolo AA, Behrendt N, Nielsen BS and Bugge TH: Intracellular collagen degradation mediated by uPARAP/ Endo180 is a major pathway of extracellular matrix turnover during malignancy. J Cell Biol 169: 977-985, 2005.

20. Madsen DH, Engelholm LH, Ingvarsen S, Hillig T, WagenaarMiller RA, Kjøller L, Gårdsvoll H, Høyer-Hansen G, Holmbeck K, Bugge TH, et al: Extracellular collagenases and the endocytic receptor, urokinase plasminogen activator receptor-associated protein/Endo180, cooperate in fibroblastmediated collagen degradation. J Biol Chem 282: 27037-27045, 2007.

21. Shi F, Harman J, Fujiwara K and Sottile J: Collagen I matrix turnover is regulated by fibronectin polymerization. Am J Physiol Cell Physiol 298: C1265-C1275, 2010.

22. Leitinger B and Hohenester E: Mammalian collagen receptors. Matrix Biol 26: 146-155, 2007.

23. Everts V, van der Zee E, Creemers L and Beertsen W: Phagocytosis and intracellular digestion of collagen, its role in turnover and remodelling. Histochem J 28: 229-245, 1996.

24. Arora PD, Manolson MF, Downey GP, Sodek J and McCulloch CA: A novel model system for characterization of phagosomal maturation, acidification, and intracellularcollagen degradation in fibroblasts. J Biol Chem 275: 35432-35441, 2000.

25. Madsen DH, Ingvarsen S, Jürgensen HJ, Melander MC, Kjøller L, Moyer A, Honoré C, Madsen CA, Garred P, Burgdorf S, et al: The non-phagocytic route of collagen uptake: A distinct degradation pathway. J Biol Chem 286: 26996-27010, 2011.

26. Wu K, Yuan J and Lasky LA: Characterization of a novel member of the macrophage mannose receptor type $\mathrm{C}$ lectin family. J Biol Chem 271: 21323-21330, 1996

27. Tesar DB, Cheung EJ and Bjorkman PJ: The chicken yolk sac IgY receptor, a mammalian mannose receptor family member, transcytoses IgY across polarized epithelial cells. Mol Biol Cell 19: 1587-1593, 2008.

28. He Y and Bjorkman PJ: Structure of FcRY, an avian immunoglobulin receptor related to mammalian mannose receptors, and its complex with IgY. Proc Natl Acad Sci USA 108: 12431-12436, 2011.

29. East $\mathrm{L}$ and Isacke $\mathrm{CM}$ : The mannose receptor family. Biochim Biophys Acta 1572: 364-386, 2002.

30. Napper CE, Drickamer K and Taylor ME: Collagen binding by the mannose receptor mediated through the fibronectin type II domain. Biochem J 395: 579-586, 2006.

31. Martinez-Pomares L, Wienke D, Stillion R, McKenzie EJ, Arnold JN, Harris J, McGreal E, Sim RB, Isacke CM and Gordon S: Carbohydrate-independent recognition of collagens by the macrophage mannose receptor. Eur J Immunol 36: 1074-1082, 2006.

32. Malovic I, Sørensen KK, Elvevold KH, Nedredal GI, Paulsen S, Erofeev AV, Smedsrød BH and McCourt PA: The mannose receptor on murine liver sinusoidal endothelial cells is the main denatured collagen clearance receptor. Hepatology 45: 1454-1461, 2007.

33. Madsen DH, Leonard D, Masedunskas A, Moyer A, Jürgensen HJ, Peters DE, Amornphimoltham P, Selvaraj A, Yamada SS, Brenner DA, et al: M2-like macrophages are responsible for collagen degradation through a mannose receptor-mediated pathway. J Cell Biol 202: 951-966, 2013.

34. Jürgensen HJ, Johansson K, Madsen DH, Porse A, Melander MC, Sørensen KR, Nielsen C, Bugge TH, Behrendt $\mathrm{N}$ and Engelholm LH: Complex determinants in specific members of the mannose receptor family govern collagen endocytosis. J Biol Chem 289: 7935-7947, 2014.

35. Ancian P, Lambeau G and Lazdunski M: Multifunctional activity of the extracellular domain of the M-type $(180 \mathrm{kDa})$ membrane receptor for secretory phospholipases A2. Biochemistry 34: 13146-13151, 1995. 
36. Takahashi S, Watanabe K, Watanabe Y, Fujioka D, Nakamura T, Nakamura K, Obata JE and Kugiyama K: C-type lectin-like domain and fibronectin-like type II domain of phospholipase $\mathrm{A}(2)$ receptor 1 modulate binding and migratory responses to collagen. FEBS Lett 589: 829-835, 2015.

37. Jürgensen HJ, Madsen DH, Ingvarsen S, Melander MC, Gårdsvoll H, Patthy L, Engelholm LH and Behrendt N: A novel functional role of collagen glycosylation: Interaction with the endocytic collagen receptor uparap/ENDO180. J Biol Chem 286: 32736-32748, 2011.

38. East L, Rushton S, Taylor ME and Isacke CM: Characterization of sugar binding by the mannose receptor family member, Endo180. J Biol Chem 277: 50469-50475, 2002.

39. Sage H, Woodbury RG and Bornstein P: Structural studies on human type IV collagen. J Biol Chem 254: 9893-9900, 1979.

40. Rivera-Calzada A, Robertson D, MacFadyen JR, Boskovic J, Isacke CM and Llorca O: Three-dimensional interplay among the ligand-binding domains of the urokinase-plasminogenactivator-receptor-associated protein, Endo180. EMBO Rep 4: $807-812,2003$

41. Boskovic J, Arnold JN, Stilion R, Gordon S, Sim RB, RiveraCalzada A, Wienke D, Isacke CM, Martinez-Pomares L and Llorca O: Structural model for the mannose receptor family uncovered by electron microscopy of Endo180 and the mannose receptor. J Biol Chem 281: 8780-8787, 2006.

42. Llorca O: Extended and bent conformations of the mannose receptor family. Cell Mol Life Sci 65: 1302-1310, 2008.

43. Sturge J, Todd SK, Kogianni G, McCarthy A and Isacke CM: Mannose receptor regulation of macrophage cell migration. J Leukoc Biol 82: 585-593, 2007.

44. Fasquelle C, Sartelet A, Li W, Dive M, Tamma N, Michaux C, Druet T, Huijbers IJ, Isacke CM, Coppieters W, et al: Balancing selection of a frame-shift mutation in the MRC2 gene accounts for the outbreak of the Crooked Tail Syndrome in Belgian Blue Cattle. PLoS Genet 5: e1000666, 2009.

45. Sartelet A, Klingbeil P, Franklin CK, Fasquelle C, Géron S Isacke CM, Georges M and Charlier C: Allelic heterogeneity of Crooked Tail Syndrome: Result of balancing selection? Anim Genet 43: 604-607, 2012.

46. Wagenaar-Miller RA, Engelholm LH, Gavard J, Yamada SS Gutkind JS, Behrendt N, Bugge TH and Holmbeck K: Complementary roles of intracellular and pericellular collagen degradation pathways in vivo. Mol Cell Biol 27: 6309-6322, 2007.

47. Madsen DH, Jürgensen HJ, Ingvarsen S, Melander MC, Albrechtsen R, Hald A, Holmbeck K, Bugge TH, Behrendt N and Engelholm LH: Differential actions of the endocytic collagen receptor UPARAP/Endo180 and the collagenase MMP-2 in bone homeostasis. PLoS One 8: e71261, 2013.

48. Inoue $\mathrm{K}$, Mikuni-Takagaki Y, Oikawa K, Itoh T, Inada M, Noguchi T, Park JS, Onodera T, Krane SM, Noda M, et al: A crucial role for matrix metalloproteinase 2 in osteocytic canalicular formation and bone metabolism. J Biol Chem 281: 33814-33824, 2006

49. Mosig RA, Dowling O, DiFeo A, Ramirez MC, Parker IC, Abe E, Diouri J, Aqeel AA, Wylie JD, Oblander SA, et al: Loss of MMP-2 disrupts skeletal and craniofacial development and results in decreased bone mineralization, joint erosion and defects in osteoblast and osteoclast growth. Hum Mol Genet 16: $1113-1123,2007$

50. Abdelgawad ME, Søe K, Andersen TL, Merrild DM, Christiansen P, Kjærsgaard-Andersen P and Delaisse JM: Does collagen trigger the recruitment of osteoblasts into vacated bone resorption lacunae during bone remodeling? Bone 67: 181-188, 2014.

51. Wu X, Spitz MR, Lee JJ, Lippman SM, Ye Y, Yang H, Khuri FR, Kim E, Gu J, Lotan R, et al: Novel susceptibility loci for second primary tumors/recurrence in head and neck cancer patients: Large-scale evaluation of genetic variants. Cancer Prev Res (Phila) 2: 617-624, 2009.

52. Yamaguchi T, Nakaoka H, Yamamoto K, Fujikawa T, Kim YI, Yano K, Haga S, Katayama K, Shibusawa T, Park SB, et al: Genome-wide association study of degenerative bony changes of the temporomandibular joint. Oral Dis 20: 409-415, 2014

53. Engelholm LH, Nielsen BS, Netzel-Arnett S, Solberg H, Chen XD, Lopez Garcia JM, Lopez-Otin C, Young MF, BirkedalHansen H, Danø K, et al: The urokinase plasminogen activator receptor-associated protein/endo180 is coexpressed with its interaction partners urokinase plasminogen activator receptor and matrix metalloprotease-13 during osteogenesis. Lab Inves 81: 1403-1414, 2001 .
54. Isacke CM, van der Geer P, Hunter T and Trowbridge IS: p180, a novel recycling transmembrane glycoprotein with restricted cell type expression. Mol Cell Biol 10: 2606-2618, 1990.

55. Howard MJ, Chambers MG, Mason RM and Isacke CM: Distribution of Endo180 receptor and ligand in developing articular cartilage. Osteoarthritis Cartilage 12: 74-82, 2004.

56. Everts V, Delaissé JM, Korper W, Jansen DC, TigchelaarGutter W, Saftig P and Beertsen W: The bone lining cell: Its role in cleaning Howship's lacunae and initiating bone formation. J Bone Miner Res 17: 77-90, 2002.

57. Bundesmann MM, Wagner TE, Chow YH, Altemeier WA, Steinbach T and Schnapp LM: Role of urokinase plasminogen activator receptor-associated protein in mouse lung. Am J Respir Cell Mol Biol 46: 233-239, 2012.

58. Engelholm LH, Nielsen BS, Dan $\varnothing \mathrm{K}$ and Behrendt N: The urokinase receptor associated protein (uPARAP/endo180): A novel internalization receptor connected to the plasminogen activation system. Trends Cardiovasc Med 11: 7-13,2001.

59. Honardoust HA, Jiang G, Koivisto L, Wienke D, Isacke CM, Larjava $\mathrm{H}$ and Häkkinen L: Expression of Endo180 is spatially and temporally regulated during wound healing. Histopathology 49: 634-648, 2006.

60. Mousavi SA, Sato M, Sporstøl M, Smedsrød B, Berg T, Kojima N and Senoo H: Uptake of denatured collagen into hepatic stellate cells: Evidence for the involvement of urokinase plasminogen activator receptor-associated protein/Endo180. Biochem J 387: 39-46, 2005.

61. Mousavi SA, Fønhus MS and Berg T: Up-regulation of uPARAP/ Endo180 during culture activation of rat hepatic stellate cells and its presence in hepatic stellate cell lines from different species. BMC Cell Biol 10: 39, 2009.

62. Ikenaga N, Ohuchida K, Mizumoto K, Akagawa S, Fujiwara K, Eguchi D, Kozono S, Ohtsuka T, Takahata S and Tanaka M: Pancreatic cancer cells enhance the ability of collagen internalization during epithelial-mesenchymal transition. PLoS One 7: e40434, 2012.

63. Wienke D, Davies GC, Johnson DA, Sturge J, Lambros MB, Savage K, Elsheikh SE, Green AR, Ellis IO, Robertson D, et al: The collagen receptor Endo180 (CD280) Is expressed on basal-like breast tumor cells and promotes tumor growth in vivo. Cancer Res 67: 10230-10240, 2007.

64. Caley MP, Kogianni G, Adamarek A, Gronau JH, RodriguezTeja M, Fonseca AV, Mauri F, Sandison A, Rhim JS, Pchejetski D, et al: TGF $31-E n d o 180-d e p e n d e n t$ collagen deposition is dysregulated at the tumour-stromal interface in bone metastasis. J Pathol 226: 775-783, 2012.

65. Huijbers IJ, Iravani M, Popov S, Robertson D, Al-Sarraj S, Jones $\mathrm{C}$ and Isacke $\mathrm{CM}$ : A role for fibrillar collagen deposition and the collagen internalization receptor endo180 in glioma invasion. PLoS One 5: e9808, 2010.

66. Schnack Nielsen B, Rank F, Engelholm LH, Holm A, Danø K and Behrendt N: Urokinase receptor-associated protein (uPARAP) is expressed in connection with malignant as well as benign lesions of the human breast and occurs in specific populations of stromal cells. Int J Cancer 98: 656-664, 2002.

67. Palmieri C, Caley MP, Purshouse K, Fonseca AV, RodriguezTeja M, Kogianni G, Woodley L, Odendaal J, Elliott K, Waxman J, et al: Endo180 modulation by bisphosphonates and diagnostic accuracy in metastatic breast cancer. Br J Cancer 108: $163-169,2013$.

68. Kogianni G, Walker MM, Waxman J and Sturge J: Endo180 expression with cofunctional partners MT1-MMP and uPAR-uPA is correlated with prostate cancer progression. Eur J Cancer 45: 685-693, 2009

69. Rodriguez-Teja M, Gronau JH, Minamidate A, Darby S, Gaughan L, Robson C, Mauri F, Waxman J and Sturge J: Survival outcome and EMT suppression mediated by a lectin domain interaction of Endo180 and CD147. Mol Cancer Res 13: 538-547, 2015.

70. Rodriguez-Teja M, Gronau JH, Breit C, Zhang YZ, Minamidate A, Caley MP, McCarthy A, Cox TR, Erler JT, Gaughan L, et al: AGE-modified basement membrane cooperates with Endo180 to promote epithelial cell invasiveness and decrease prostate cancer survival. J Pathol 235: 581-592, 2015.

71. Stupp R, van den Bent MJ and Hegi ME: Optimal role of temozolomide in the treatment of malignant gliomas. Curr Neurol Neurosci Rep 5: 198-206, 2005.

72. D'Abaco GM and Kaye AH: Integrins: Molecular determinants of glioma invasion. J Clin Neurosci 14: 1041-1048, 2007.

73. Payne LS and Huang PH: The pathobiology of collagens in glioma. Mol Cancer Res 11: 1129-1140, 2013. 
74. Takahashi S, Yamada-Okabe H, Hamada K, Ohta S, Kawase T, Yoshida K and Toda M: Downregulation of uPARAP mediates cytoskeletal rearrangements and decreases invasion and migration properties in glioma cells. J Neurooncol 103: 267-276, 2011.

75. Mundy GR: Mechanisms of bone metastasis. Cancer 80 (Suppl): 1546-1556, 1997.

76. St Croix B, Rago C, Velculescu V, Traverso G, Romans KE, Montgomery E, Lal A, Riggins GJ, Lengauer C, Vogelstein B, et al: Genes expressed in human tumor endothelium. Science 289: $1197-1202,2000$

77. Gai X, Tu K, Lu Z and Zheng X: MRC2 expression correlates with TGF $\beta 1$ and survival in hepatocellular carcinoma. Int J Mol Sci 15: 15011-15025, 2014

78. Sulek J, Wagenaar-Miller RA, Shireman J, Molinolo A, Madsen DH, Engelholm LH, Behrendt $\mathrm{N}$ and Bugge TH: Increased expression of the collagen internalization receptor uPARAP/Endo180 in the stroma of head and neck cancer. J Histochem Cytochem 55: 347-353, 2007.

79. Madsen DH, Jürgensen HJ, Ingvarsen S, Melander MC, Vainer B, Egerod KL, Hald A, Rønø B, Madsen CA, Bugge TH, et al Endocytic collagen degradation: A novel mechanism involved in protection against liver fibrosis. J Pathol 227: 94-105, 2012.
80. López-Guisa JM, Cai X, Collins SJ, Yamaguchi I, Okamura DM, Bugge TH, Isacke CM, Emson CL, Turner SM, Shankland SJ, et al: Mannose receptor 2 attenuates renal fibrosis. J Am Soc Nephrol 23: 236-251, 2012.

81. Rohani MG, Chow YH, Razumova MV, Ash S, Hung CF and Schnapp LM: uPARAP function in cutaneous wound repair. PLoS One 9: e92660, 2014.

82. Oppel T and Korting HC: Actinic keratosis: The key event in the evolution from photoaged skin to squamous cell carcinoma. Therapy based on pathogenetic and clinical aspects. Skin Pharmacol Physiol 17: 67-76, 2004.

83. Tang S, Lucius R, Wenck H, Gallinat S and Weise JM: UV-mediated downregulation of the endocytic collagen receptor, Endo180, contributes to accumulation of extracellular collagen fragments in photoaged skin. J Dermatol Sci 70: 42-48, 2013.

84. Shim JH, Shin DW, Noh MS and Lee TR: Reduced collagen internalization via down-regulation of MRC2 expression by UVA irradiation and its recovery by all-trans retinoic acid. J Dermatol Sci 73: 163-166, 2014.

85. Taylor ME: Evolution of a family of receptors containing multiple C-type carbohydrate-recognition domains. Glycobiology 7: v-viii, 1997. 